\title{
CREATION OF DEFECTS CATALOGUE FOR NONCONFORMING PRODUCT IDENTIFICATION IN THE FOUNDRY ORGANIZATION
}

\author{
DOI: 10.12776/QIP.V17I2.238
}

\author{
ANDREA SÜTŐOVÁ, MARKO GRZINČIČ
}

\section{INTRODUCTION}

Automotive industry is the largest market for aluminium castings. The increasing use of aluminium castings in automotive industry during recent years is associated with its benefits such as high strength to weight ratio, corrosion resistance and ability to achieve complex designs and easy customization (Tuttle, R.B., 2012). Examples of the casting components are engine blocks, cylinder heads, transmission parts, suspensions, brakes, wheels, etc.

Castings production is a complex process involving several sub-processes such as mould and coremaking, melting, casting (pouring the metal into the mould), fettling and finishing sub-processes which affect product quality. All of these processes can generate various types of defects (Vijayaram, et al. 2006). Defect is defined as non-fulfilment of a requirement related to an intended or specified use (ISO 9000, 2006). The production of castings free from defects is one of the major challenges in the aluminium foundry industry. However, the causes of defects are often complex and defective castings occure during castings production in foundries. All foundry processes generate a certain level of defects that is closely related to the type of casting, the processes used and the equipment available (Zimwara, et al. 2013). The rejected castings can only be re-melted and the value addition during various processes is lost. High casting rejection levels have a considerable adverse effect on productivity, delivery performance and customer satisfaction. Defects cause financial losses and in addition to financial losses, delivery of defective products can cause loss of customer and organization goodwill. The organization shall ensure that product which does not conform to product requirements is identified and controlled to prevent its unintended use or delivery (ISO/TS 16949:2009). In mass production the early detection of defects and taking an appropriate corrective action is nessesary. Before taking any corrective action, the defects need to be diagnosed correctly. The proper classification and identification of a particular defect is fundamental for determination of the cause and appropriate corrective action in order to prevent 
defect recurrence (Fröhlich, L., Kozel, Š., 2004). Very often so called quick fixes and fast solutions are taken that may solve the situation for a while, but also complicate it even more. System of defects classification provide an important tool for correct casting deffects diagnostic. Defects classification of castings in a literature or currently adopted by foundries are either based on their geometry/location or on their origin or specific causes (Mane, Sata and Khire, 2010). STN 421240 standard "Castings defects terminology and classification of defects" is the basis for defects systematization, which classifies defects into seven categories (STN 42 1240, 1964): 1) defects of shape, weight and dimension, 2) surface defects, 3) discontinuities, 4) cavities, 5) macrostructure inclusions and macrostructure defects, microstructure defects, 7) defects of chemical composition and properties. The defects specified in the standard are numbered according to their categories and types. This classification was modified and extended during the long term practice with keeping up the seven standardized categories, which are divided into several groups and most of these groups are further divided and contain particular types of defects. The defects have three code numbers given by defect category, group and type (Elbel, et al., 1992). The classification is primarily used for iron based alloy castings. So far there is no specific classification for aluminium castings. Catalogues of casting defects valid in general are often unusable for particular casting technology and many foundries create their own defects catalogues. Therefore, the names of defects very often do not mean the same defects with the same development genesis (Bolibruchová, Grzinčič, 2012). In order to provide a useful tool for correct defect identification and classification, defects catalogues shall consist of: a) defect number, b) description and defect visualization, c) detection method of defect, d) causes of defect, f) corrective actions to eliminate defect causes. After defect identification and classification there are following ways of dealing with defective casting: a) casting is unrepairable and is rejected as a nonconformity, b) casting is repairable and can be released after rework and reverification, c) casting is released under concession by the customer.

\section{CREATION OF DEFECTS CATALOGUE IN THE FOUNDRY ORGANIZATION}

\subsection{Organization specification and initial state of the issue}

The organization specializes in the production of aluminum powertrain components and has manufacturing facilities located in different countries. The defects catalogue was created in one of the facilities producing cylinder heads through Gravity Semi Permanent Mold and Direct Casting technologies. The foundry continually seeks opportunities for improvements and reduction of scraps and reworks. The foundry has visual defect catalogues involving names of defects, its visualizations and brief descriptions. This catalouge, however, is not entirely complete. There are no numbers of defects according to the foundry internal document - List of defects, which involves all defects occuring in the 
foundry. In adition, defects are not classified and some defects involved in the List of defects are not in the catalouge. Some defect names in the catalogue are not the same as those in the List of defects. There is a lack of information about particular defects. The goal was to create a defects catalogue summarizing all existing defects, to classify them systematically and extend information about them to provide useful tool for classification and identification of the defects. The catalogue was created on the basis of the information gained from the literature and internal organization documents (existing Visual catalogues, List of defect, FMEA documents).

\subsection{Proposal of classification and design}

For the basic classification it was proposed to classify defects into 8 categories. First category includes the most of defects divided into two groups. The defects within the categories are classified according to related processes. The categories involve following types of defects:

\section{1) defects of shape and dimension:}

- shape and dimension defects of the core: core fin, incorrect dimension of the core, core shift caused by off-set of the core box, bent core, incorrect dimension or shape caused by worn-out core box, defects caused by gluing of the core,

- missing parts of the casting and other shape defects, dimension defects: poured short, misrun, missing part of the core, mold shift, core shift, deformed casting, mechanical damage - pouring, incorrect casting dimensions, damage by sawing on TRIDEM, mechanical damage by casting decoring, incorrect sawing, bent - fettling, incorrect grinding fettling, mechanical damage-fettling, incorrect CNC setup, incorrect CNC machining caused by tool failure, off dimension caused by incorrect casting setting - CNC.

2) surface defects: surface defects of the core, surface sticks, rough surface sticks, scabs, leaks, irregular surface caused by bad coating of the mold, rubbing the wall of the mold, irregular surface - incorrect CNC machining, other surface defects,

3) discontinuities - cracks in the core, broken core during transport, cracks in the casting, breaks or cracks of cores in the casting, cold shut.

4) cavities - open shrinkages, closed shrinkages, hydrogen bubbles, core gas bubbles, foam, bubbles, leakage.

5) macrostructure and microstructure defects - sand inclusions, inclusionsmelting, inclusions - casting.

6) defects of chemical composition and properties - inccorect chemical composition, unacceptable mechanical properties.

7) other defects - first casting after mold heating, defect caused by new setting up, core with old dimension, casting with old dimensions, defects during 
process development and others, which can not be classified into previous categories.

8) external defects - this category involves defects caused by external processes.

Basic categories are similar to above mentioned defects classification in STN 42 1240 except for last two categories (other defects, external defects). In comparison with defects classification mentioned in the literature overview, the created classification system and defect nomenclature is modified and adjusted to the organization processes and casting technology. Figure 1 illustrates part of the defects classified into first category, which is divided into two groups of defects: a) dimensional and shape defects of core, b) missing parts of casting and other shape defects, dimensional defects.

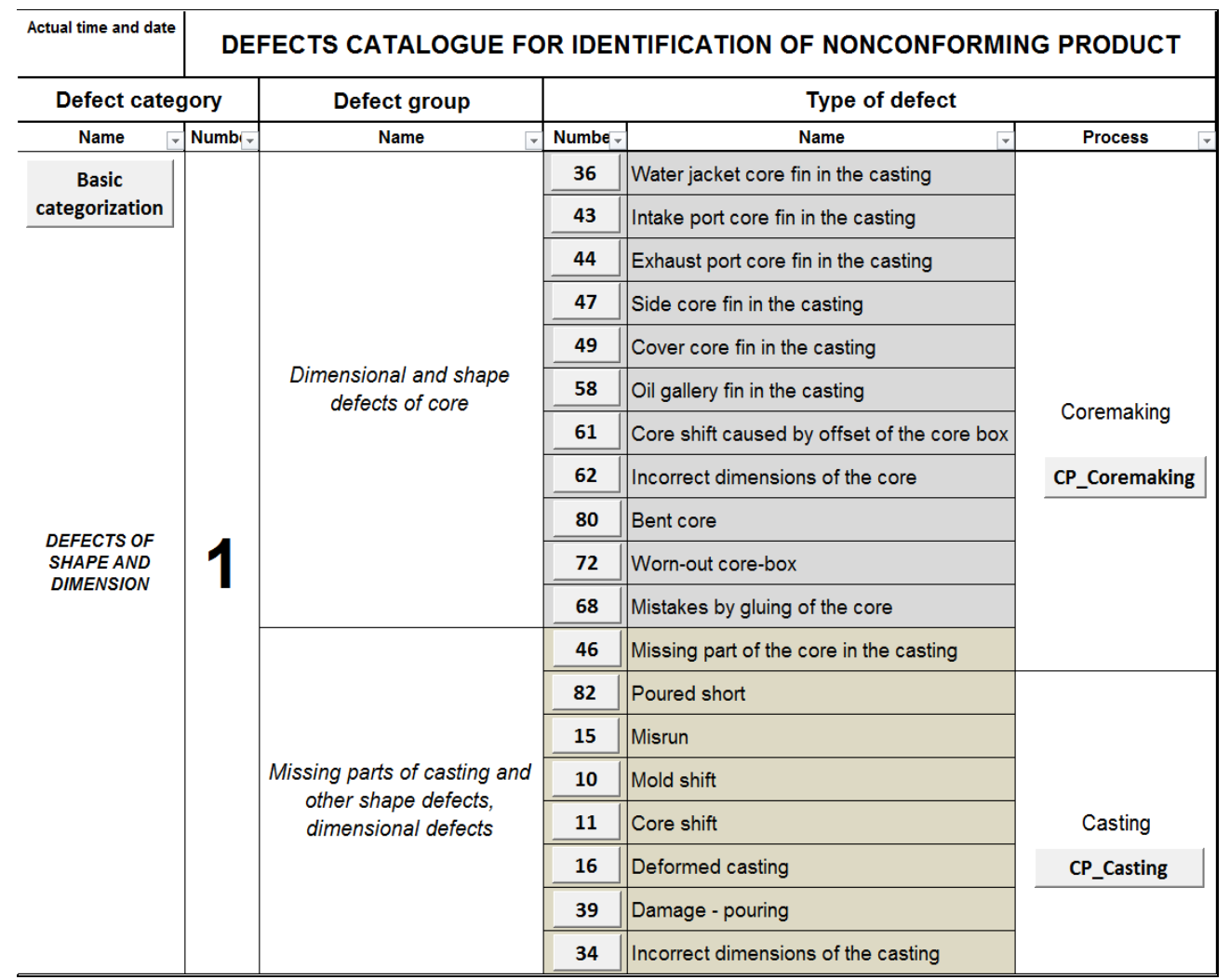

Figure 1 - Part of defects classified into the category "Defects of shape and dimension"

The catalogue is created in MS Excel and through Visual Basic is ensured the linkage with process control plans. Figure 2 illustrates an example of the selected defect - sand inclusions in the catalogue. 


\begin{tabular}{|l|c|c|c|c|}
\multicolumn{4}{|c|}{ Casting defect } \\
\hline \multicolumn{2}{|c|}{ Back to category } & \multicolumn{4}{|c|}{ MACROSCOPIC AND } \\
CATEGORY & 5 & DEFECT TYPE & Defect number \\
\cline { 3 - 4 } & Inclusions & Sand inclusions & & FMEA \\
\hline
\end{tabular}

\section{DEFECT DESCRIBTION:}

Cavities or surface imperfections on castings completely or partially filled with molding material, sand. Inclusions are caused by sand washing into the mold during the pouring.

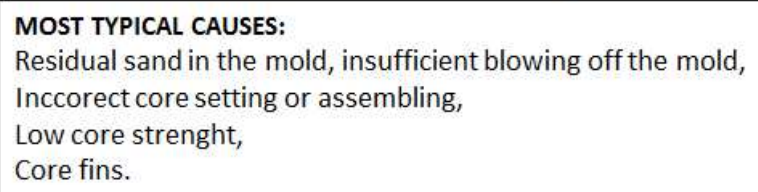

\section{DEFECT DETECTION:}

$100 \%$ visual control.

\section{DEFECT PREVENTION:}

Process of blowing off the mold,

Control the core in the mold.

\section{DEFECT VISUALIZATION:}

Sand inclusions - residual sand in the mold, incorrect core setting
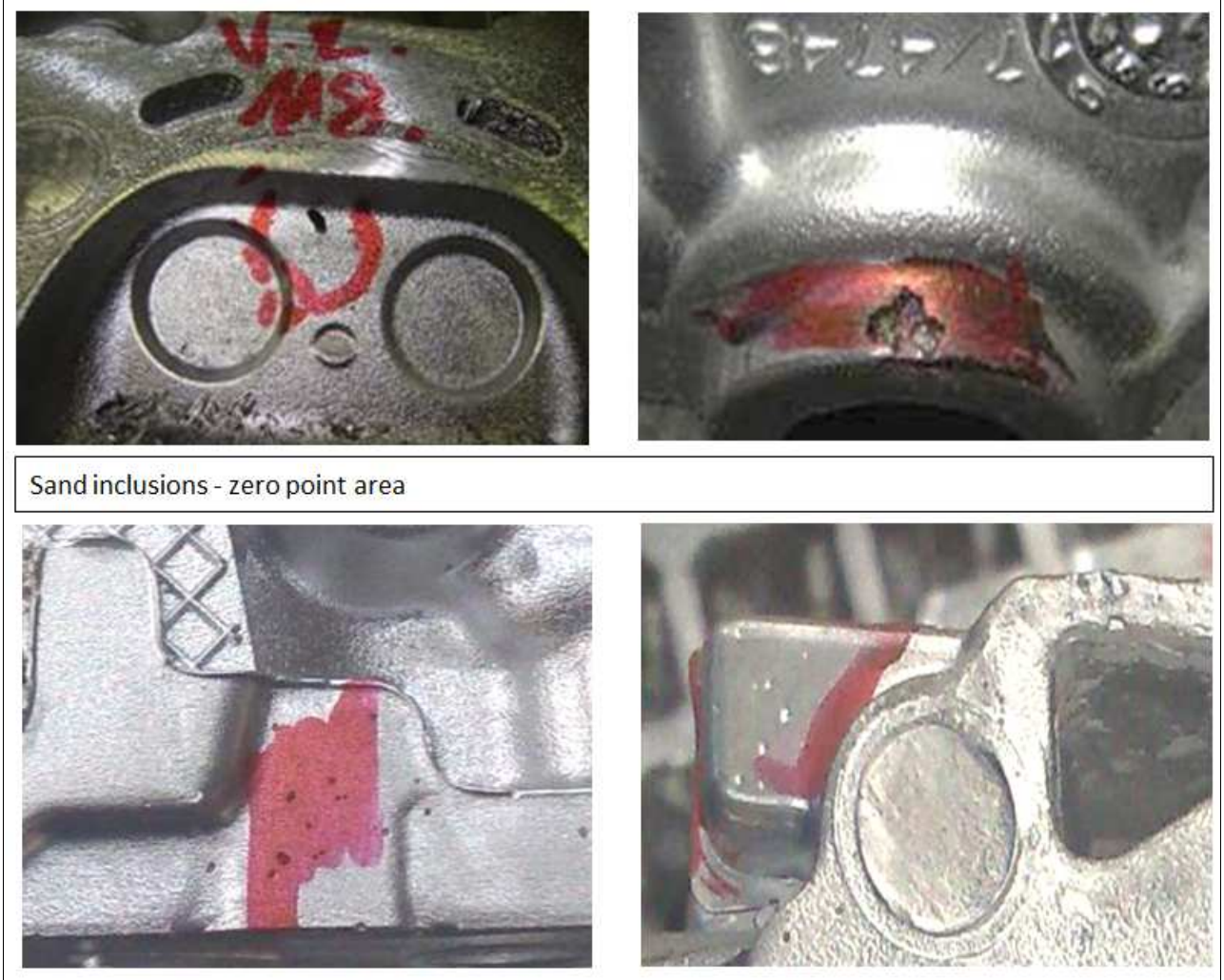

Figure 2 - Sand inclusions 
Information related to each defect comprise identification number according to List of defects, defect description, most typical causes of defect, defect detection method, defect prevention and defect visualization.

Numbers of defects in the catalogue are the same as those in the List of defects. The defects have not been renumbered according to categories and adjusted to the classification until now. It is assumed that it will be done in the future and numbering will be also changed in other related documents.

The created visual catalogue is linked with internal process FMEA and reacts to changes in FMEA or in some reasonable cases changes in the catalogue need to be transferred to FMEA. It provides an indisputable benefit, that actions related to qualitative deviations are visually supported and are more visible than in FMEA.

\section{DISCUSSION AND CONCLUSION}

The ambition of the catalogue, which was fulfilled is cumulation of various documents into a new one. The catalogue was implemented into the documentation of quality management system as a visual support. The catalogue should help in the processes of coremaking, melting, casting, fettling, heat treatment, $\mathrm{CNC}$ finalizing and quality control. The systematic defects classification and information about particular defects contribute to higher autonomy of operators and help them in the case of defect occurence to decide and deal with defective castings correctly. The catalogue also serves as a visual tool during quality control and provides to employees better orientation among defects. The catalogue prevents confusions and helps to classify and indentify defects correctly according to category and defect type. It subsequently also enables a reliable monitoring of defect occurence and trends. The catalogue is appreciated by employees in the foundry because of its logical structure and instigates thinking in the same way.

The catalogue is a living document and can be extended by process engineers with new defects, which may occure in the future or with new information related to existing defect causes, defect prevention and its detection. The catalogue is an active know-how holder and helps to support lessons learned through production portfolio of the foundry. One of the main risks in the foundry is not particularly know-how leakage by sophisticated methods but just a loss of employees by their retirement or leaving. This fact indicates another benefit provided by the catalogue. It is a future vision to create online catalogue on production lines through touchscreen monitors and offer the catalogue to other manufacturing facilities. 


\section{REFERENCES}

Bolibruchová, D. and Grzinčič, M., 2012. "Chyby hliníkových odliatkov odlievaných do kovových foriem", in Proceedings of the International conference - Vyhne`12 Produktivní ř́zení slévarny, Vyhne, 25-26 September, pp. 110-122.

Elbel, T., et al., (1992). Vady odlítku se slítin železa - klasifikace, př́činy a prevence, MATECS, Brno.

Frőhlich, L. and Kozel, Š., 2004. Atlas vád odliatkov, TU, Košice.

International Organization for Standardization, 2009. ISO/TS 16949:2009. Quality managment systems - Particular requirements for the application of ISO 9001:2000 for automotive production and relevant service part organizations. Geneva: ISO.

International Organization for Standardization, 2005. ISO 9000:2005. Quality managment systems - Fundamentals and vocabulary. Geneva: ISO.

Mane, V. V., Sata, A. and Khire M.Y., 2010. "New approach to casting defect classification and analysis supported by simulation", in Proceedings of The 59th Indian Foundry Congress, Chandigarh, February, pp. 87-104.

Slovenská technická norma/Slovak Technical Standard, 1964. STN 42 1240: 1964. Chyby odliatkov. Názvoslovie a triedenie chýb. SÚTN: Bratislava.

Tuttle, R.B., 2012. Foundry engineering: The Metallurgy and design of castings, CreateSpace.

Vijayaram, T. R. et al., 2006. "Foundry quality control aspects and prospects to reduce scrap rework and rejection in metal casting manufacturing industries", Journal of Materials Processing Technology, Vol. 178, No. 1-3, pp. 39-43.

Zimwara D., et al., 2013. "Cost of Quality as a Driver for Continuous Improvement - Case Study - Company X", International Journal of Innovative Technology and Exploring Engineering, Vol. 2, No. 2, pp. 132-139.

\section{ABOUT AUTHORS}

Andrea Sütőová, Ing., PhD. is a lecturer at the Department of Integrated Management, Faculty of Metallurgy, Technical University of Košice, Letná 9, 04200 Košice, Slovakia, e-mail: andrea.sutoova@tuke.sk

Marko Grzinčič, Ing., Dr. is an external lecturer at the University J. E. Purkyně in Ústí nad Labem, Faculty of Production Technology and Management, Department of Technology and Material Engineering, Na Okraji 1001/7, 40001 Ústí nad Labem, Czech Republic, e-mail: mgrzincic@yahoo.de 